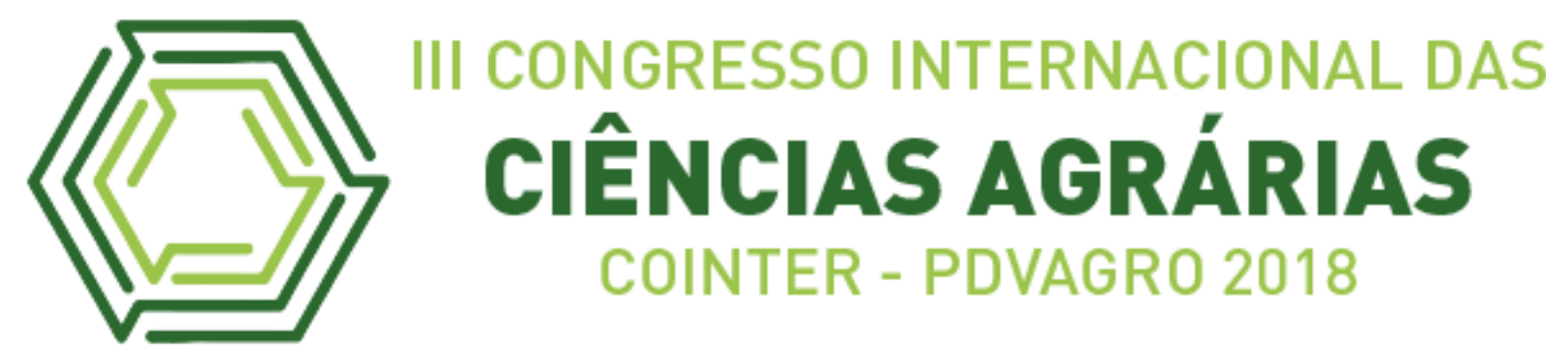

\title{
CARACTERÍSTICAS QUÍMICAS DE UM LATOSSOLO SOB PASTAGEM NO SUDESTE PARAENSE
}

\section{CHEMICAL CHARACTERISTICS OF A LATOSOL UNDER PASTURE IN SOUTHEAST PARAENSE}

\begin{abstract}
Thamires Oliveira Gomes ${ }^{1}$; Jhuan Santana Brito ${ }^{2}$; Marcus Victor Almeida Campos ${ }^{3}$; Seidel Ferreira dos Santos ${ }^{4}$; Gleidson Marques Pereira ${ }^{5}$
\end{abstract}

\section{DOI: https://doi.org/10.31692/2526-7701.IIICOINTERPDVAGRO.2018.00354}

\section{Introdução}

Tem sido muito comum em regiões tropicais e subtropicais áreas de pastagens em estado de degradação causando prejuízos ambientais e econômicos nas regiões. No Brasil $50 \%$ das áreas de pastagens em áreas de importância ecológica, estão em processo de degradação ou já degradadas, representando cerca de 30 milhões de hectares na Amazônia Legal. A caracterização de pastagem como degradada se dá ligado relativamente à região ou nível tecnológico da propriedade, ou seja, a ideal produtividade para a pastagem na região em questão (DIAS FILHO, 2011).

Das áreas desmatadas no território Amazônico, apresentam 45\% deste total sendo substituídas áreas de vegetação nativa em pastagens, se destacando o estado do Pará como um dos três estado com maiores índices de desmatamento. A pecuária tem impacto ecológico negativo na Amazônia devido sua implantação geralmente ser feita após o corte e queima da vegetação nativa, onde nos primeiros anos de implantação dos pastos, apresentam alta produtividade, devido à incorporação das cinzas que gera maior fertilidade, porém posteriormente perdem essa característica, ocasionando a degradação da área.

O processo de degradação das pastagens leva a diminuição gradativa da sua capacidade de suporte, causando perdas em sua qualidade. É necessário entender as causas e consequências deste processo para que se possam sugerir formas de recuperação ou

\footnotetext{
${ }^{1}$ Graduanda em Engenharia Florestal; Universidade do Estado do Pará; thamires.o.gomes@gmail.com

${ }^{2}$ Graduando em Engenharia Florestal; Universidade do Estado do Pará; Jhuanbrito5@outlook.com

${ }^{3}$ Engenheiro Ambiental; Universidade do Estado do Pará; marcusvictor.campos@gmail.com

${ }^{4}$ Doutor em Biodiversidade e Biotecnologia da Rede Bionorte; Universidade Federal do Amazonas; botanish@yahoo.com.br

${ }^{5}$ Mestre em Solos e Nutrição de Plantas; Universidade Federal do Ceará; eng.gleidson.uepa@gmail.com
} 
manutenção das pastagens, as causas da degradação podem ser por meio de atividades inadequadas de pastejo, manejo inadequado pela ausência de adubação ou uso exacerbado de fogo nessas áreas, falhas na formação da pastagem devido o preparo inadequado da área de implantação, e fatores bióticos e abióticos.

O desenvolvimento da pecuária no Pará juntamente com os problemas enfrentados devido a sua degradação deve ser analisado para fim de se fornecer práticas para a recuperação da produtividade das áreas de pastejo, bem como auxiliar os produtores de forma a evitar o desmatamento de novas áreas para a geração de pastos. Nesse sentido, o presente trabalho objetivou determinar as alterações nas propriedades químicas do solo sob pastagem (Brachiaria brizantha) em distintas condições de manejo.

\section{Fundamentação Teórica}

A agricultura é uma atividade dependente da natureza que sem condições adequadas de solo, clima, água, ou seja, condições favoráveis, há a diminuição dos seus recursos bases, até tornar-se insustentável (ANDRIOLI, 2008). Notadamente, a adoção da agricultura, ao promover o surgimento de campos de cultivo - que numa definição sumária, constituem nada mais, nada menos do que "ecossistemas simplificados" - de forma intrínseca, derivou em alterações ambientais abruptas (WALDMAN, 2011).

Segundo Matias (2003), devido à grande pressão do uso dos recursos naturais em função do aumento da população e às técnicas de manejo que têm sido utilizadas para o cultivo, nem sempre há a preocupação com a sustentabilidade do sistema. Essas técnicas utilizadas de forma inadequada causam a degradação do solo

Dias-Filho (2011) comenta que a caracterização de indicadores da degradação de pastagens é uma tarefa difícil, por não existir metodologia uniforme para este fim. Sendo a caracterização de indicadores de degradação de uma pastagem relativa à produtividade considerada ideal para a mesma, um nível de produção pode definir uma pastagem degradada em um local, mas pode determinar uma pastagem ainda produtiva para outro.

\section{Metodologia}

\section{Descrição da área de estudo}

Segundo o Instituto de Terras do Pará - ITERPA (2017), projeto de assentamento (PA) São Francisco, localizado no município de Eldorado dos Carajás (sudeste paraense), foi criado em 14 de julho de 1997, contendo 257 famílias distribuídas em um total de 7140 hectares. O estudo foi conduzido no lote 102 , nome Sítio Santa Lúcia, situada à latitude $05^{\circ} 55^{\prime 2} 21^{\prime \prime}$ (S) e 
longitude $49^{\circ} 11^{\prime} 52,9^{\prime \prime}$ (W). Altitude média local de $140 \mathrm{~m}$, temperatura média anual de $26,5^{\circ} \mathrm{C}$ e a precipitação média anual de aproximadamente $1.757 \mathrm{~mm}$. O solo em que predomina a agricultura pertence ao grande grupo Latossolo Vermelho-Amarelo, que é caracterizado com alto teor de argila.

\section{Coleta das amostras de solo e análise estatística}

Foram coletadas, no Sítio Santa Lúcia, amostras de solo formadas de capim braquiarão (Brachiaria brizantha) com tratamentos definidos como um ano de reforma (P1), dois anos de reforma (P2) e área de pastagem de 30 anos de idade sem reforma (P3). O delineamento utilizado foi o inteiramente casualizado com quatro parcelas (repetições) em cada tratamento. As coletas (Figura 01) foram realizadas no início do segundo semestre do ano de 2018, caracterizado pelo verão amazônico. No total foram coletadas 12 amostras compostas, as quais foram submetidas a análises de parâmetros químicos do solo (Teor de Nitrogênio - N, Fósforo - P, Potássio - K e Matéria Orgânica - MO) no Laboratório de Solos da Embrapa Amazônia Oriental, localizado em Belém-PA. Os dados foram submetidos à análise de variância, e, quando significativos, analisados pelo teste de Tukey (SISVAR).

Figura 01 - Fluxograma para coleta de amostra.

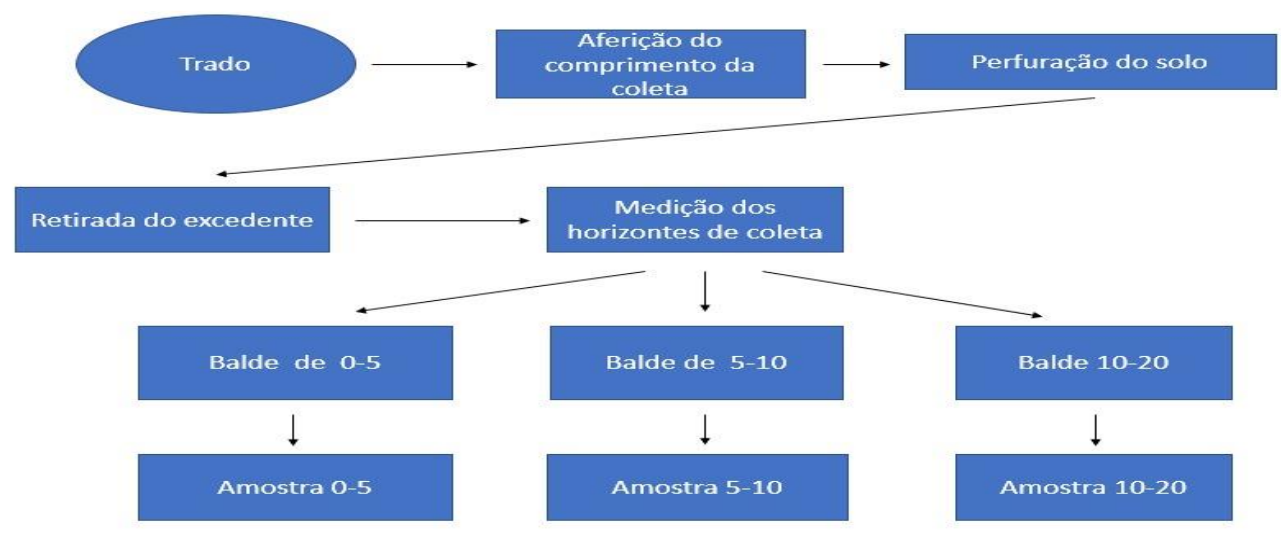

Fonte: Autores, 2018.

\section{Resultados e Discussões}

Nos manejos de solo avaliados, foram observados baixos teores de MO, e uma diminuição dos teores com o aumento da profundidade nos perfis, como mostra a tabela 01 . Fontana et al, (2011), observou resultados semelhantes, que explica a diminuição do teor de MO com a substituição de mata nativa por áreas de pastagens devido a diminuição de resíduos na camada superficial e o aumento das atividades microbianas. Os dados mostraram ainda que a área P1 se destaca como o tratamento mais intemperizado em relação aos teores de MO, explica-se por ser o mais recente a substituir sua vegetação natural e também pelo método de 
queima utilizada nessas regiões, diminuindo assim a presença de $\mathrm{MO}$ e contribuindo para o empobrecimento do seu potencial produtivo (CASTILHOS e JACQUES, 1984).

Tabela 01 - Teores de MO $(\mathrm{g} / \mathrm{kg}), \mathrm{N}(\mathrm{g} / \mathrm{kg}), \mathrm{P}\left(\mathrm{mg} / \mathrm{dm}^{3}\right)$ e $\mathrm{K}\left(\mathrm{mg} / \mathrm{dm}^{3}\right)$ no solo, sua interação em diferentes tempos de pastagem e diferentes profundidades coleta de solo e respectivos níveis de significância ${ }^{1}$.

\begin{tabular}{|c|c|c|c|c|}
\hline $\begin{array}{c}\text { Profundidade } \\
(\mathrm{cm})\end{array}$ & $\begin{array}{l}\text { MO } \\
(\mathrm{g} / \mathrm{kg})\end{array}$ & $\begin{array}{c}\mathbf{N} \\
(\mathrm{g} / \mathrm{kg})\end{array}$ & $\begin{array}{c}\mathbf{P} \\
\left(\mathrm{mg} / \mathrm{dm}^{3}\right)\end{array}$ & $\begin{array}{c}\mathrm{K} \\
\left(\mathrm{mg} / \mathrm{dm}^{3}\right)\end{array}$ \\
\hline \multicolumn{5}{|c|}{ P1 } \\
\hline $0-5$ & $18,24 \mathrm{a}$ & $1,15 \mathrm{a}$ & $2,50 \mathrm{a}$ & $157,00 \mathrm{a}$ \\
\hline $5-10$ & $17,22 \mathrm{a}$ & $1,22 \mathrm{a}$ & $1,50 \mathrm{a}$ & $90,00 \mathrm{a}$ \\
\hline $10-20$ & $14,26 \mathrm{a}$ & $0,95 \mathrm{a}$ & $2,00 \mathrm{a}$ & $78,75 \mathrm{a}$ \\
\hline \multicolumn{5}{|c|}{$\mathbf{P 2}$} \\
\hline $0-5$ & $26,27 \mathrm{a}$ & $1,47 \mathrm{a}$ & $3,75 \mathrm{a}$ & $160,75 \mathrm{a}$ \\
\hline $5-10$ & $23,77 \mathrm{a}$ & $1,28 \mathrm{a}$ & $1,75 \mathrm{a}$ & $156,00 \mathrm{a}$ \\
\hline $10-20$ & $21,00 \mathrm{a}$ & $1,11 \mathrm{a}$ & $1,50 \mathrm{a}$ & $140,75 \mathrm{a}$ \\
\hline \multicolumn{5}{|c|}{ P3 } \\
\hline $0-5$ & $31,69 \mathrm{a}$ & $1,15 \mathrm{a}$ & $222,75 \mathrm{a}$ & $28,50 \mathrm{~b}$ \\
\hline $5-10$ & $17,13 \mathrm{a}$ & $0,96 \mathrm{a}$ & $177,00 \mathrm{a}$ & $263,75 \mathrm{a}$ \\
\hline $10-20$ & $12,50 \mathrm{a}$ & $1,11 \mathrm{a}$ & $1,50 \mathrm{a}$ & $140,75 \mathrm{a}$ \\
\hline
\end{tabular}

${ }^{1}$ Médias de mesmas letras não diferem entre si pelo teste de Tukey a 5\% de probabilidade.

Os teores de $\mathrm{N}$ apresentados na tabela 01 variaram de $1,15 \mathrm{~g} / \mathrm{kg}(\mathrm{P} 1), 1,47 \mathrm{~g} / \mathrm{kg}(\mathrm{P} 2) \mathrm{e}$ $1,15 \mathrm{~g} / \mathrm{kg}$ (P3), não apresentando diferença significativa na profundidade $0-5$, nas demais camadas do solo, a área P2 apresentou tendência de maiores teores nas camadas, enquanto a área P3 foi a que apresentou os menores teores, porém sem apresentar diferenças significantes. O nitrogênio apresenta formas altamente solúveis, sendo facilmente perdido por lixiviação, por redução desse macronutriente a formas gasosas e por volatilização da amônia, por ter alta mobilidade no solo, atingindo facilmente o volume de solo explorado pelas raízes, o que explica o baixo teor deste elemento no solo de pastagens (SCHUNKE et al., 2001). Podendo ser explicada também principalmente pela baixa fertilidade natural, pelo tempo de uso dos pastos e também pela falta de reposição dos nutrientes.

$\mathrm{O}$ elemento $\mathrm{P}$ apresentou diferença significativa na área $\mathrm{P} 3$, sendo o tratamento com maior teor deste elemento, principalmente nas profundidades 0-5 e 5-10. De acordo com Carvalho-Pupatto et al, (2004), o P tem baixo potencial de mobilidade no solo, não estando sujeito a perdas por lixiviação, justificando a grande quantidade deste elemento armazenada no pasto mais antigo, baixo teor desse elemento causa baixa produtividade, podendo ocasionar danos às pastagens. Ceretta et al, (2010), confirmou maior presença de P nas camadas superficiais e sua diminuição de acordo com o aumento da profundidade. Vilar et al, 
(2010), explica o acúmulo excessivo de P, devido a capacidade de solos intemperizados possuírem alto potencial pedogenético e baixo número de espécies minerais, o que provoca maior retenção do elemento nesses solos.

A liberação de K dos solos pode ser pelas formas não-trocáveis e a reação de adsorção eletrostática influenciando diretamente na concentração deste elemento em solos com cargas variáveis, e o seu movimento se dá predominantemente por fluxo de massa, tendo grande capacidade dependendo das condições de alcançar as profundidades. Explicando a alta concentração $\mathrm{K}$ no solo, não havendo disparidades significativas nos tratamentos e profundidades. $\mathrm{O} \mathrm{K}$ tem ainda alta mobilidade, sendo superior a movimentação do $\mathrm{N}$, e muito inferior à do $\mathrm{P}$, o que se contradiz nesta pesquisa, podendo ser justificado pelo período seco em que foram realizadas as coletas dificultando assim a lixiviação do macronutriente (ERNANI et al., 2007).

\section{Conclusões}

As pastagens não apresentaram diferenças na qualidade do solo conforme o manejo imposto em cada área estudada. Com a presença de animais em pastejo, resultou na maior redução de qualidade nos solos com braquiária com trinta anos sem nenhum tipo de correção nutricional. Contudo, os tratos culturais realizados na pastagem mais jovens, com reforma e calagem, promoveram melhorias no solo. E, notadamente, na área mais nova (P1), a significativa contribuição dos atributos químicos foram pouco afetados pelo uso do solo, possivelmente pela expressiva contribuição da matéria orgânica produzida pelas gramíneas.

\section{Referências}

ANDRIOLI, A. I. Agricultura familiar e sustentabilidade ambiental. Revista Espaço Acadêmico, n. 89, Rio Grande do Sul, UNIJUI, out., p. 1-4., 2008.

CARVAlHO-PUPATTO, J. G., BULL, L. T., \& CRUSCIOL, C. A. C. Atributos químicos do solo, crescimento radicular e produtividade do arroz de acordo com a aplicação de escórias. Pesquisa Agropecuária Brasileira, v. 39, n. 12, p. 1213-1218, 2004.

CASTILHOS, Z.M.S.; JACQUES, A.V.A. Produção e qualidade de uma pastagem natural submetida a tratamentos de introdução de trevo vesiculoso cv. Yuchi (Trifolium vesiculosum 
Savi), ceifa e queima. Porto Alegre: Secretaria da Agricultura Estado Rio Grande do Sul, v.11, p.65-112, 1984.

CEREtTA, C. A., LOREnSini, F., BRUnetTO, G., GIROTTO, E., GATIBONI, L. C., LOURENZI, C. R., MIOTTO, A. Frações de fósforo no solo após sucessivas aplicações de dejetos de suínos em plantio direto. Pesquisa Agropecuária Brasileira, v. 45, n. 6, p. 593$602,2010$.

DIAS-FILHO, M. B. Degradação de pastagens: Processos, Causas e Estratégias de Recuperação. 4. ed. Belém: MBDF, 215p., 2011.

ERNANI, P. R., BAYER, C., ALMEIDA, J. A. D., \& CASSOL, P. C. Mobilidade vertical de cátions influenciada pelo método de aplicação de cloreto de potássio em solos com carga variável. Revista brasileira de ciência do solo. Campinas. Vol. 31, n. 2, p. 393-402, 2007.

FONTANA, A., FIGUEIRA da SILVA, C., PEREIRA, M. G., LOSS, A., JOSINO de BRITO, R., \& de MELO BENITES, V. Avaliação dos compartimentos da matéria orgânica em área de Mata Atlântica. Acta Scientiarum. Agronomy, v. 33, n. 3, 2011.

MATIAS, M. I. A. S. Influência da cobertura vegetal na disponibilidade de nutrientes e na distribuição do sistema radicular em Latossolo Amarelo coeso de Tabuleiro Costeiro. 2003. 78f. - Universidade Federal da Bahia, Cruz das Almas, Ba, 2003.

SCHUNKE, R. M. Alternativas de manejo de pastagem para melhor aproveitamento do nitrogênio do solo. Embrapa Gado de Corte, 2001.

VILAR, C. C.; COSTA, A. C. S.; HOEPERS, A.; SOUZA JUNIOR, I. G. Capacidade máxima de adsorção de fósforo relacionada a formas de ferro e alumínio em solos subtropicais. Rev. Bras. Ciênc. Solo, Viçosa, V. 34, n. 4, 2010.

WALDMAN, M. Crise ambiental: Ponderando a respeito de um dilema da modernidade. Revista Crítica Histórica. v. 2, n. 4,2011. 